\title{
Características Enunciativas Presentes em Textos Históricos de Divulgação Científica e Possíveis Contribuições ao Ensino
}

\author{
Filipe Silva de Oliveira \\ Edson José Wartha
}

\begin{abstract}
Resumo
História da Ciência e Ensino de Ciências são áreas do conhecimento com possibilidades de interface anunciadas e investigadas na atualidade, desse modo, produzindo conhecimento a comunidade de pesquisa interessada em encontrar caminhos didáticos para a sala de aula. Por meio de Narrativas Históricas (NHs), Estudo de Caso e sistematicamente Sequências Didáticas, essa interface tem sido desenvolvida. O estudo de textos históricos de divulgação científica auxilia a compreender a divulgação do conhecimento científico para o público comum no passado, acredita-se ser possível o uso desses textos na construção de materiais didáticos como Narrativas Históricas (NHs) e Estudo de Caso. Neste artigo discutimos características enunciadas em textos de divulgação científica escritos por um divulgador da ciência brasileiro, relacionando essas características na construção de Narrativas Históricas que venham a utilizar os textos desse divulgador. As características são conteúdo temático, composição do enunciado e estilo verbal. Essas características auxiliam na compreensão dos textos desse divulgador no processo de construção das Narrativas Históricas.
\end{abstract}

Palavras-chave: Ensino de Ciências. História da Ciência. Divulgação Científica. Narrativa Histórica.

\begin{abstract}
History of Science and Science Teaching are areas of knowledge with possibilities of interface announced and investigated today, thus, producing knowledge to the research community interested in finding didactic paths for the classroom. Through Historical Narratives (NHs) Case Study and systematically Instructional Sequences, this interface been developed. The study of historical texts of scientific popularization assist to understand the popularization scientific knowledge to the common public in the past, it is believed that the use of these is possible in the construction of instruction materials such as Historical Narratives (NHs) and Case Study. In this paper we discuss characteristics stated in scientific popularization texts written by a Brazilian science disseminator, relating these characteristics in the construction of Historical Narratives that come to use the texts of disseminator. Features are thematic content, statement composition and verbal style. These characteristics assist in the understand of the texts of this disseminator in the process of construction the Historical Narratives.
\end{abstract}

Keywords: Science Teaching. History of Science. Scientific Popularization. Historical Narrative.

\section{INTRODUÇÃO}

Estudos em torno de atividades de divulgação científica no Brasil tem sido explorados sob diferentes aspectos, perpassando pela compreensão dessa atividade enquanto tal (caracterização, delimitação conceitual, etc.), assim como a discussão em torno de seu uso ou não, aplicado ao ensino. É 
possível identificar nos trabalhos de Massarani (1998) ${ }^{1}$ e Bueno $(2010)^{2}$ a preocupação em delimitar as atividades de divulgação científica de uma maneira geral, bem como no jornalismo científico, ramo do jornalismo que trabalha com a divulgação científica. Especificamente no ensino de ciências há trabalhos como o de Roqueplo (1974)3 , Barros (1992)4 e Bragança Gil e Lourenço (1999)5 apud Marandino et al. $(2003)^{6}$ que entendem ser as atividades de divulgação científica próprias para falar da cultura científica, não sendo cabível ao ensino, por entenderem haver objetivos específicos distintos em ambas atividades.

Por outro lado, Nascimento e Cassiani $(2009)^{7}$ e Machado $(2001)^{8}$ tecem em suas pesquisas apontamentos para o uso de textos de divulgação científica na formação de professores, além disso, autores como Chaves et al. (2001) ${ }^{9}$, Correa (2003) $)^{10}$, Ramalho e Silva (2005) ${ }^{11}$ e Giordan et al. (2019) 12 utilizaram textos de divulgação científica como material didático nas salas de aula da Educação Básica, sendo que Giordan et al. (2019) ${ }^{13}$ inseriram textos de divulgação científica numa Sequência Didática, discutindo o tema da fosfoetanolamina como substância que foi prometida como cura para o câncer no

\footnotetext{
${ }^{1}$ Luisa. Massarani, "A divulgação científica no Rio de Janeiro: algumas reflexões sobre a década de 20" (dissertação de mestrado, Universidade Federal do Rio de Janeiro, 1998), 14-31.

2 Wilson Bueno. "Comunicação científica e divulgação científica: aproximações e rupturas conceituais," Revista Informação e Informação 15, (esp. 2010):1-12.

3 Philippe Roqueplo, La partage du savoir (Paris: Éditions du Sueli, 1974), citado em Martha Marandino et al, A educação não-formal e a divulgação científica: O que pensa quem faz? (Bauru: Abrapec, 2003), 1.

${ }^{4}$ Henrique G. de P. L. de Barros, Quatro cantos de origem (Rio de Janeiro: Revista Perspicillium, 1992), citado em Marandino et al, Educação não-formal e a divulgação científica: O que pensa quem faz? (Bauru: Abrapec, 2003), 1.

${ }^{5}$ Fernando Bragança Gil, Que cultura para o século XXI? O papel essencial dos museus de ciência e técnica (Rio de Janeiro: Museu de Astronomia e Ciências Afins, 1999), citado em Marandino et al, $A$ educação não-formal e a divulgação científica: O que pensa quem faz? (Bauru: Abrapec, 2003), 1. ${ }^{6}$ Martha Marandino et al. " A Educação não formal e a divulgação científica: o que pensa quem faz." In IV Encontro Nacional de Pesquisa em Educação em Ciências, org. Marco Antônio Moreira (Bauru: Abrapec, 2003: 1-13.

7 Tatiana Galieta Nascimento; Suzani Cassiani, "Leituras de divulgação científica por licenciandos em Ciências Biológicas." Revista Electrónica de Enseñanza de las Ciencias (2009): 745-769, https:/reec.uvigo.es/REEC/Spanish/REEC_older_es.htm. (acessado em 13 de julho de 2016).

8 José Luis Michinel Machado, "O Funcionamento de textos divergentes sobre energia com alunos de Física. A leitura no Ensino Superior." (tese de doutorado, Universidade Estadual de Campinas, 2001), 1220.

9 Taniamara V. Chaves; Joviane Mezzomo; Eduardo A. Terrazzan, "Textos de divulgação científica como recurso didático para o ensino-aprendizagem da Física clássica: exemplos em termodinâmica e eletromagnetismo", in III Encontro Nacional de Pesquisa em Educação em Ciências (III ENPEC) (Atibaia: ABRAPEC, 2001): 1.

${ }^{10}$ Ana L., Lopes Correa, "A prática de leitura e escrita de alunos do ensino médio sobre física moderna e contemporânea" (dissertação de mestrado, Universidade Federal de Minas Gerais, 2003), 7-207.

11 Marina Ramalho e Silva, orgs., Ciência para todos. 13 vols. (Rio de Janeiro: Prefeitura da Cidade do Rio de Janeiro, 1-98).

12 Marcelo Giordan, et al., "Polêmica da Fosfoetanolamina no Ensino de Química: articulações entre o planejamento de ensino e a comunicação científica" Química Nova na Escola 41 (2019): 327-334, http://qnesc.sbq.org.br/online/qnesc41 4/04-QS-89-18.pdf (acessado em 19 de dezembro de 2020). 13 Ibid.
} 
Brasil. Neste artigo trabalhamos com o entendimento de que a divulgação científica em suas variadas formas pode ser útil para fins didático-pedagógicos.

Considerando a discussão feita inicialmente entende-se que a divulgação científica feita ao longo da história da ciência desde seu início, é e foi válida enquanto atividade de divulgação para a sociedade e deve ser estudada, em especial na didática das ciências, inclusive que seja útil para o ensino, a aprendizagem, a construção e o compartilhamento dos saberes produzidos e em circulação, preferencialmente por meio da divulgação científica produzida textualmente. Incluído a isto, em textos históricos de divulgação científica, deve-se levar em conta aspectos do tratamento em que se dava 0 conhecimento científico abordado; o contexto sócio histórico; aspectos historiográficos e o gênero discursivo da época.

O que denominamos aqui por Textos Históricos de Divulgação Científica representam um material importante para a investigação em história da ciência, podendo ser utilizados no estabelecimento de relações entre a história da ciência e o ensino, tanto para compreensão de aspectos da natureza da ciência bem como em aspectos conceituais no entendimento de como um conceito foi desenvolvido, inclusive como material didático. O que anunciamos no parágrafo anterior vem sendo praticado por meio de Estudos de Caso e Narrativas Históricas não somente com textos de divulgação científica, como com outros materiais históricos de interesse.

Todos os textos analisados neste estudo foram escritos pelo divulgador da ciência João Ribeiro. Escritor e intelectual brasileiro nascido no Estado de Sergipe, e que morou boa parte de sua vida na cidade do Rio de Janeiro (capital do Brasil à época), tendo escrito artigos de divulgação científica sobre diversos assuntos, a jornais brasileiros no período sócio histórico de 1895 a 1934, num momento de transformações relevantes para a ciência e o mundo. Este período, desde o início século XIX é marcado pela institucionalização da ciência e seu interesse pelo público em geral, promovendo a mundialização da cultura científica, ainda no século XIX divulgar ciência era denominado pela expressão "vulgarização científica" (termo em desuso na atualidade por ser pejorativo) (VERGARA, 2008)14.

Entendemos que seus escritos no campo da divulgação científica são relevantes para a História da Ciência e o Ensino de Ciências e que, podem ser explorados principalmente sob a abordagem externalista da história da ciência, visto que os escritos de João ribeiro podem ser considerados a materialidade do gênero discursivo de sua época e de seu lugar de fala.

\footnotetext{
${ }^{14}$ Moema de Rezende Vergara, "Ensaio sobre o termo "vulgarização científica" no Brasil do século XIX" Revista Brasileira de História da Ciência 1 (2008): 137-145, https://www.sbhc.org.br/revistahistoria/view?ID REVISTA HISTORIA=12 p. 137-145 (acessado em20 de maio de 2020).
} 
Em artigo anterior, discutimos sobre que visões de ciência eram transmitidas ao leitor através desse material (OLIVEIRA; WARTHA, 2018) ${ }^{15}$. Neste artigo apresentamos uma análise de três textos deste divulgador que ajudam a compreender o estilo da escrita dos textos de divulgação científica no início do século XX no Brasil, identificando características enunciativas que auxiliem durante a elaboração de materiais didáticos como as Narrativas Históricas (NHs). Relacionado a isto, discutimos o papel deste tipo de material na compreensão crítica do que são descobertas científicas no ensino de ciências, aspecto da natureza da ciência analisado, e que é trabalhado em NH. Logo, o objetivo deste artigo é discutir características enunciativas presentes em textos históricos de divulgação científica com a intenção de fornecer elementos que auxiliem na construção de narrativas históricas.

\section{CONSIDERAÇÕES INICIAIS}

Na literatura que investiga a inserção da história da ciência no ensino há vários apontamentos que ensejam como desafios a esse processo, principalmente na formação de professores, lugar onde se acredita começar a estabelecer o desenvolvimento de propostas, alguns aspectos são citados, a saber: 0 processo de aplicação da abordagem histórico-filosófica no Ensino Médio apresenta ausência de material didático e pedagógico; dificuldade de leitura e interpretação por parte dos estudantes; a não facilidade em trabalhar com esta abordagem (MARTINS, 2007) ${ }^{16}$.

No que concerne a dificuldade de ausência de material didático e pedagógico, ressalta-se que iniciativas em relação ao uso de textos de divulgação científica vem sendo utilizados diretamente em situações de planejamento didático, (MARTINS et al., 200417/ FERREIRA; QUEIROZ, 201118/ ZANCHETA JUNIOR, 201019/ GIORDAN et al., 201920), em outra linha de trabalho há autores que vem analisando a presença desses textos em livros didáticos (SOUZA; ROCHA, 2017) 21.

\footnotetext{
${ }^{15}$ Filipe Silva de Oliveira; Edson José Wartha, "A visão de ciências do jornalista João Ribeiro em artigo de divulgação científica" Revista Debates em Ensino de Química 4 (2018): 78-101, http://www.journals.ufrpe.br/index.php/REDEQUIM/article/view/1648/482482611 p. 78-101 (acessado em 20 de novembro de 2019).

${ }^{16}$ André Ferrer Pinto Martins. "História e filosofia da ciência no ensino: há muitas pedras nesse caminho..." Caderno Brasileiro de Ensino de Física 24 (2007):112-131, https://periodicos.ufsc.br/index.php/fisica/article/view/6056 (acessado em 02 de dezembro de 2019).

17 Isabel Martins; Tatiana Galieta Nascimento; Teo Bueno de Abreu, "Clonagem na sala de aula: um exemplo do uso didático de um texto de divulgação científica" Investigações em Ensino de Ciências 9 (2004): 95-111, https://www.if.ufrgs.br/cref/ojs/index.php/ienci/article/view/536/331 (acessado em 02 de dezembro de 2019).

18 Luciana Nobre de Abreu Ferreira; Salete Linhares Queiroz, "Autoria no ensino superior de química: análise de textos escritos por alunos de graduação" Ciência \& Educação 17 (2011): 41-558, http://www.scielo.br/scielo.php?script=sci arttext\&pid=S1516-73132011000300003 (acessado em 02 de dezembro de 2019).

19 Juvenal Zanchetta Junior, "Circulação de textos midiáticos entre alunos de escola pública básica" Educação e Pesquisa 36 (2010): 297-310,
} 
Até aqui entende-se haver iniciativas e trabalhos que procuram investigar a natureza da divulgação científica e sua capacidade de inserção no ensino de ciências, principalmente através de textos de divulgação científica. Discutiremos ao longo do artigo aspectos relativos à linguagem e estrutura de textos históricos de divulgação científica. Para tanto, consideramos utilizar a perspectiva de análise dos gêneros discursivos proposta por Bakhtin (1929/1995)22, por ter vivido e produzido este conhecimento no período de produção dos artigos que analisamos, além de ser um suporte teórico adequado aos objetivos levantados. $O$ discurso é uma característica humana das suas relações que é essencial para interpretação do pensamento humano, seus atos, compromissos, crenças e valores num período histórico. Importante ressaltar que nos apoiamos no material historiográfico de Vergara $(2008)^{23}$ e Oliveira (1997/1998)2425 para compreender o período de divulgação científica do Brasil no século XIX e início do século XX.

Estamos interessados em verificar as características enunciativas nos textos históricos do divulgador da ciência João Ribeiro, visto que por meio deles é possível obter informações da época, úteis ao desenvolvimento de materiais didáticos como as narrativas históricas ( $\mathrm{NHs}$ ), para uso em sala de aula. Ao exibirmos as características enunciativas destes textos, fornecemos mais elementos que auxiliem na produção destes materiais. É com esse entendimento que acreditamos ser possível compreender os materiais textuais analisados neste artigo, bem como propor o uso de narrativas históricas no ensino de ciências, em face de uma interação com a história da ciência.

\section{MOTIVOS QUE JUSTIFICAM DIDATICAMENTE A ANÁLISE PROPOSTA}

Por qual motivo utilizar a análise de gêneros discursivos para os textos do divulgador João Ribeiro? Chegaremos a uma resposta...

\footnotetext{
http://www.scielo.br/scielo.php?script=sci arttext\&pid=S1517-97022010000100007 (acessado em 02 de dezembro de 2019).

20 Ibid., 2.

${ }^{21}$ Pedro Henrique Ribeiro de Souza; Marcelo Borges Rocha, "Análise da linguagem de textos de divulgação científica em livros didáticos: contribuições para o ensino de Biologia" Ciência \& Educação 23 (2017):321-340,

http://www.scielo.br/scielo.php?script=sci abstract\&pid=S151673132017000200321\&lng=en\&nrm=is o\&tlng=pt (acessado em 02 de dezembro de 2019).

22 Mikhail Bakhtin (Volochinov), Marxismo e filosofia da linguagem (São Paulo: Editora Hucitec, 1929/1995).

23 Ibid., 3.

${ }^{24}$ José Carlos de Oliveira, "A cultura científica e a Gazeta do Rio de Janeiro" Revista Brasileira de História da Ciência 17(1997): 29-58, https://www.sbhc.org.br/revistahistoria/view?ID REVISTA HISTORIA=25 (acessado em 25 de maio de 2020).

25 José Carlos de Oliveira, "Os periódicos portugueses de Inglaterra e a cultura científica brasileira (1808-1821)" Revista Brasileira de História da Ciência 19 (1998): 31-62, https://www.sbhc.org.br/revistahistoria/view?ID REVISTA HISTORIA=23 (acessado em 25 de maio de 2020).
} 
As narrativas históricas (NHs) são um material didático que constituem uma forma de contar uma história científica voltada ao ensino, sabe-se que uma boa história atrai a atenção do ouvinte, e seu uso no ensino não é recente em sala de aula (KLASSEN, 200926; NORRIS et al., 200527), imagine ser possível discutir um determinado conteúdo da Química inicialmente por meio de uma história, essa é a questão, ao mesmo tempo esses autores também apontam não haver uma tradição metodológica sobre 0 assunto, passando a inaugurar uma tendência metodológica, entre esses e outros autores. Para Norris et al. $(2005)^{28}$ existem dois tipos de NHs, as intrínsecas a ciência e as externas a ciência, o primeiro tipo é um material que está atrelado ao conteúdo científico propriamente dito, enquanto que o segundo tipo de narrativa contempla aspectos do contexto sócio cultural, motivações, crenças e perspectivas dos cientistas.

Seguindo o modelo do Losango Didático (MEHÉUT, 2005) ${ }^{29}$ para analisar sequências de ensino e aprendizagem, Silva e Wartha $(2018)^{30}$ destacam que um material didático deve ter um equilíbrio entre 0 que é epistêmico e pedagógico, entendendo ser o eixo epistêmico aquele que estabelece uma relação entre o conhecimento científico e o mundo material, enquanto que o eixo pedagógico encontra relação entre professores e estudantes. Uma $\mathrm{NH}$, embora um material didático menos complexo que uma sequência didática (pode estar inserida numa SD), encontra respaldo no que afirmam os autores na tentativa de estar próxima do equilíbrio esperado, por contemplar os eixos epistêmico e pedagógico.

Em outro estudo para compreender como estudantes aprendem Química e Física, Pozo e Crespo (2009) 31 sintetizam ao final quatro procedimentos gerais que devem ser adotados para a aprendizagem, que são, aquisição de informação; interpretação da informação; compreensão da informação e comunicação da informação. Destacamos o uso de $\mathrm{NHs}$ como materiais didáticos ao processo de ensino e aprendizagem no desenvolvimento dos procedimentos de sublinhar e selecionar a informação dos textos escritos (aquisição de informação), assim como os procedimentos de exposição oral e escrita (comunicação da informação). Isto ocorre por conta da estrutura das NHs que favorecem e promovem esses procedimentos que acontecem em sala de aula e às vezes não são sistematizados ou

\footnotetext{
${ }^{26}$ Stephen Klassen, "The construction and analysis of a science story: a proposed methodology" Science \& Education 18 (2009): 401-423.

${ }^{27}$ Stephen P. Norris.; Sandra M. Guilbert.; Martha L. Smith.; Shahram Hakimelahi.; Linda M. Phillips, "A Theoretical framework for narrative explanation in science" Science Education 89 (2005): 535-563, www.interscience.wiley.com (acessado em 21 de maio de 2020).

28 Ibid., 5.

${ }^{29}$ Martine Méheut, "Teaching-learning sequences tools for learning and/or research". In Research and quality of science education Ed. Kerst Boersma et al., 195-207. Dordrecht: Springer, 2005.

${ }^{30}$ Erivanildo Lopes da Silva.; Edson José Wartha, "Estabelecendo relações entre as dimensões pedagógica e epistemológica no Ensino de Ciências" Ciência \& Educação 24 (2018): 337-354 https://www.scielo.br/pdf/ciedu/v24n2/1516-7313-ciedu-24-02-0337.pdf (acessado em 30 de maio de 2020).

31 Pozo, Juan Ignacio \& Crespo, Miguel Ángel Gómez. A aprendizagem e o ensino de ciências: do conhecimento cotidiano ao conhecimento científico, 5a ed. (Porto Alegre: Artmed, 2009), 186.
} 
são operados racionalmente sem intencionalidade e tomada de consciência, tanto por professores como por estudantes.

As NHs devem ter uma estrutura que considere três aspectos: i) aspecto histórico; ii) aspecto da natureza da ciência; iii) aspecto literário (KLASSEN, 200932; NORRIS et al., 200533; KUBLI, 200134). Aqui não explicaremos em detalhe esta questão metodológica, pois não se trata do objeto discutido neste texto, o intuito foi apenas de demonstrar haver na literatura uma discussão sobre o assunto quanto a esta forma de abordar história e ensino de ciências, ver também (SANTOS et al., 201835; SCHIFFER; GUERRA, 201536; SCHIFFER; GUERRA, 201937).

Entendemos não haver uma forma melhor de introduzir e explicar um conteúdo de alcance teórico se não por meio de uma narrativa, algo que cative o estudante inicialmente, apesar de saber pela própria literatura que as narrativas históricas apresentam limitações, que não são um problema em si, pelo contrário, discute-se sua utilidade para a inserção de questionamentos, por não apresentarem respostas prontas, transmitirem uma imagem da ciência que seja adequada, e garantir a ideia de que 0 conhecimento científico é também histórico e inacabado, dentre outros. O que a narrativa histórica não garante, é ser um instrumento único para o ensino, além disso, deve ser aplicada em sala de aula com uma orientação pedagógica, o papel do professor é sempre crucial em sala de aula (SCHIFFER; GUERRA, 2019) ${ }^{38}$.

Como as NHs, os textos históricos de divulgação científica aqui analisados envolvem uma atividade discursiva, logo, é cabível a análise bakhtiniana dos gêneros discursivos. A intenção pedagógica dessa análise é cercar o material textual de informações discursivas que vão ser úteis na construção das NHs fundamentadas na tradição que está sendo desenvolvida. Isto porque NHs são comumente associadas ao ensino por tornarem o conteúdo ensinado mais memorável, porque estimula a imaginação,

\footnotetext{
32 Ibid., 5.

33 Ibid., 5.

${ }^{34}$ Fritz Kubli, "Can the Theory of Narratives Help Science Teachers be Better Storytellers?" In: Science education and culture: the contribution of history and philosophy of science, org. Fábio Bevilacqua.; Enrico Giannetto.; Michael R. Matthews (Dordrecht: Springer - Science + Busness Media, B.V. 2001): 179.

35 Jucilene S. Santos.; Filipe S. Oliveira.; Maísa Pereira de Jesus.; Edson J. Wartha, "Texto de divulgação científica do jornalista João Ribeiro com potencial para construção de narrativas históricas," in Anais do XIX Encontro Nacional de Ensino de Química, org. Adriano A. Silva \& Gahelyka Agtha P. Souza (Rio Branco: Biblioteca da UFAC, 2018), 1-12.

${ }^{36}$ Hermann Schiffer \& Andréia Guerra, "A utilização de narrativas históricas na construção do conceito de energia: um estudo de caso," in Anais do VIII Encontro Nacional de Pesquisa em Educação em Ciências, org. Isabel Martins \& Marcelo Giordan (Campinas: ABRAPEC, 2011), 1-12.

37 Hermann Schiffer \& Andréia Guerra, "Problematizando práticas científicas em aulas de Física: o uso de uma história interrompida para se discutir ciência de forma epistemológica-contextual" Revista Brasileira e Pesquisa em Educação em Ciências 19 (2019): 95-127, https://periodicos.ufmg.br/index.php/rbpec/issue/view/278 (acessado em 21 de maio de 2020) ${ }^{38}$ Ibid., 6.
} 
devido a capacidade do ser humano de organizar suas experiências e memórias por meio da narração (HADZIGEORGIOU, 201139; SCHIFFER; GUERRA, 201940), uma potencialidade humana.

A NH deve propiciar interesse do leitor pela história contada, facilitando a abordagem de conteúdos e introdução de conceitos (SCHIFFER; GUERRA, 201941; KLASSEN, 200942), ainda é demonstrado que o efeito emocional das $\mathrm{NHs}$ é melhor em resultados com a memória de longo prazo do que a aplicação de exercícios. Como apontam Schiffer e Guerra $(2015, \text { p. } 5)^{43}$ temos ciência e,

"Não esperamos que a construção de textos literários seja uma das principais habilidades de professores de ciências, inclusive a construção de narrativas. 0 desafio se amplia ao pensarmos na construção de textos narrativos com caráter histórico, de modo que devemos tomar certos cuidados ao trilhar este caminho."

Apesar disso, os autores entendem que o professor ao trabalhar com NHs alcance a habilidade com este material, e pode se tornar um bom contador de histórias (SCHIFFER; GUERRA, 2015) ${ }^{44}$.

\section{AS CATEGORIAS ADOTADAS NESTE ESTUDO}

Para Bakhtin os usos da linguagem realizam-se na forma de,

[...] enunciados concretos, únicos e proferidos por sujeitos participantes das interações sociais que ocorrem em determinados campos de atividades. Esses campos, ou esferas sociais, não apenas saturam e significam os enunciados de determinadas projeções ideológicas, valorativas e de sentidos como, em adição, os consubstanciam de determinadas condições de produção e finalidades discursivas, que se materializam no conteúdo temático, no estilo e na composição dos enunciados (PEREIRA; RODRIGUES, 2010, p. 149)45.

Assim os enunciados são caracterizados por serem únicos, irrepetíveis quanto a eventicidade, do ponto de vista histórico eles são dialógicos, sendo balizados pelos gêneros, legitimando e significando

\footnotetext{
39 Yannis Hadzigeorgiou.; Stephen Klassen.; Cathrine Froese Klassen, "Encouraging a "Romantic Understanding" of Science: The Effect of the Nikola Tesla Story" Sci \& Educ 21 (2012): 1111-1138, https://doi.org/10.1007/s11191-011-9417-5 (acessado em 23 de maio de 2020).

40 Ibid., 6.

41 Ibid., 6.

42 Ibid., 6.

43 Ibid., 6.

44 Ibid., 6.

45 Rodrigo Acosta Pereira.; Rosângela Hammes Rodrigues, "Os gêneros discursivos sob perspectiva da análise dialógica de discurso do círculo de Bakhtin" Letras 20 (2010): 147-162,

https://periodicos.ufsm.br/letras/issue/view/661/showToc (acessado em 22 de maio de 2020).
} 
a produção de novos enunciados, sendo histórico-culturalmente situados, além de serem estáveis, flexíveis, dinâmicos e fluídos, devendo ser investigados a partir de sua historicidade, pois não são estruturas convencionais ou textos escritos num formato, mas tipos de enunciados de natureza social, discursiva, histórica, cultural e dialógica (PEREIRA; RODRIGUES, 2010, p. 149)46.

A ferramenta metodológica de análise da linguagem proposta por Bakhtin $(2006)^{47}$ deve seguir os passos: a) estudar as formas da língua e as situações de interação verbal a partir das condições sociais em que se realizam essas formas e essas situações; $b$ ) investigar as formas dos diferentes enunciados em ligação com a situação de interação de que constituem seus elementos, c) examinar, a partir daí, as formas da língua na sua interpretação habitual. Esta sequência "inicia-se pela identificação do contexto social, passando pelos gêneros até chegar às formas gramaticais" (MOTTA-ROTH, 2008, p. 356) ${ }^{48}$, as formas gramaticais não entram como escopo do nosso estudo.

Por isso enquadramos os textos de João Ribeiro como provenientes de um gênero discursivo próprio de sua época, pois o vemos como um sujeito sócio-histórico, sendo um homem que conviveu em vários ambientes socioculturais, inclusive em terras europeias. Sabe-se que o mesmo era professor e foi um sujeito de filosofia livre. Entende-se que as relações do meio em que ele viveu são incisivas para a formação da sua visão de ciência, impregnadas no texto. 0 divulgador viveu o período do auge do Romantismo de movimento artístico, político, filosófico e literário, de origens localizadas na Alemanha e na Inglaterra, iniciado no século XVIII e continuando até o século XIX, (RIBEIRO, s.d) ${ }^{49}$, além de ter sido influenciado pelo movimento cultural da Escola de Recife, encabeçado por pessoas como Tobias Barreto, Joaquim Nabuco e Silvio Rômero.

Outra característica que consideramos importante a um texto histórico de divulgação científica que deve ser analisada é como as descobertas científicas são tratadas. Em geral textos de divulgação científica lidam com a publicação de avanços em ciência que são novos, é comum, casos de espetacularização do feito, referindo-se apenas a indivíduos. Em geral quando se trata de assuntos relativos a natureza da ciência ocorre uma ampla discussão com muita polissemia e foco em determinados aspectos, alguns autores como Lederman et al. $(2002)^{50}$ e Matthews (2012) 51 procuraram demarcar um

\footnotetext{
46 Ibid.

47 Mikhail Bakhtin (Volochinov, V. N.), Marxismo e filosofia da linguagem: problemas fundamentais do método sociológico na ciência da linguagem. 12. ed. (São Paulo: Hucitec, 2006).

48 Désirée Motta-Roth, "Análise crítica de gêneros: contribuições para o ensino e a pesquisa de linguagem" D.E.L.T.A. 24 (2008): 341-383, https://revistas.pucsp.br/delta/issue/view/1599 (acessado em 22 de maio de 2020).

49 Joaquim Ribeiro. 9 mil dias com João Ribeiro. $1^{\text {a }}$ ed. Rio de Janeiro: Ed. Record, s.d.

50 Norman G. Lederman; Fouad Abd-el-khalick; Randy L. Bell; Renée S. Schwartz, "Views of nature of science questionnaire: toward valid and meaningful assessment of learners'conceptions of nature of science" Journal of research in science teaching 39 (2002): 497-521, http://www.gb.nrao.edu/ sheather/For Sarah/lit\%20on\%20nature\%20of\%20science/views\%20of\%2 0nature\%20of\%20science\%20questionnaire.pdf (acessado em 5 de setembro de 2019).
} 
consenso sobre o assunto, definindo o que são aspectos consensuais e características da ciência, respectivamente.

Neste artigo discute-se 0 assunto das descobertas científicas sob o olhar teórico de Lakatos (1999)52 e Kuhn (1998)53, ambos os autores compreendiam o tema descoberta científica como algo característico num contexto específico, para Kuhn a descoberta científica só existia quando fatores experimentais e a teoria estavam articulados, contudo não se dava aí a revolução científica, mas sim, quando ocorria uma mudança de paradigma, que era precedido por crises ao paradigma vigente, em suma, a descoberta estava muito mais alinhada a crises do paradigma, do que ao processo de revolução científica em si.

$\mathrm{Na}$ visão epistemológica de Imre Lakatos (SILVEIRA, 1996)54 (LAKATOS, 1999)55 os experimentos colaboravam para que cientistas pudessem definir entre um programa de pesquisa e outro, o mesmo também discutiu que não existem experimentos revolucionários na história da ciência, sendo um mito construído em episódios da pesquisa, o papel da descoberta não estava só atrelado a experimentos, mas ao desenvolvimento ou não dos programas de pesquisa, os chamados programas progressivos apresentavam novas informações, enquanto que programas de pesquisa regressivos, acabavam por não possuírem novas descobertas, a revolução se da, quando os cientistas abandonam o programa regressivo em detrimento do progressivo.

Não é diferente na química e na transmissão de sua imagem no ensino, em química orgânica o experimento conhecido como síntese de Wöhler, em que foi produzido em laboratório a uréia (cianeto de amônio) é tido como o divisor de águas de um postulado existente à época, havia uma ideia de que substâncias orgânicas somente eram sintetizadas por seres vivos (teoria da força vital). Tem-se transmitido que a partir desta síntese em laboratório a química orgânica se desenvolveu, tratando-se de um experimento revolucionário, contudo Vidal e Porto (2011) ${ }^{56}$ discutem por meio desse episódio da história da ciência que na verdade o que é apresentado nos livros didáticos como um fator decisivo, é contraposto a estudos de historiadores da ciência, estes, argumentam que haviam várias doutrinas que

\footnotetext{
${ }^{51}$ Matthews, Michael R. "preâmbulo para Changing the focus: from nature of science (NOS) to features of science (FOS)" in Advances in Nature of Science Research, org M.S. Khine, 3-26. (Zurique: Springer Netherlands, 2012): 268.

52 Imre Lakatos. Falsificação e metodologia dos programas de investigação científica. (São Paulo: Almedina, 1999), 1-207.

53 Thomas S. Kuhn. A Estrutura das revoluções científicas. (São Paulo: Pesrpectiva, 1998), 1-257.

54 Fernando Lang da Silveira, "A metodologia dos programas de pesquisa: a epistemologia de Imre lakatos" Caderno catarinense de Ensino de Física 13 (1996): 219-230, https://www.if.ufrgs.br/ lang/Textos/LAKATOS.pdf (acessado em 05 de setembro de 2019). 55 Ibid.

${ }^{56}$ Paulo Henrique Vidal; Paulo Alves Porto, "Algumas contribuições do episódio histórico da síntese da uréia para o ensino de Química" Revista História da Ciência e Ensino: Construindo Interfaces 4 (2011): 13-23, https://revistas.pucsp.br/hcensino/article/view/6013/5766 (acessado em 5 de setembro de 2019).
} 
explicavam a força vital, o vitalismo era uma delas, e que o artigo publicado por Friedrich Wöhler (18801882) em 1828 na verdade apresentava o interesse do pesquisador em descrever uma substância nova com aspectos semelhantes a úreia.

Em outro artigo, Rocha e Silva (2019) ${ }^{57}$ desenvolveram uma Sequência de Ensino e Aprendizagem (SEA) numa abordagem contextual para discutir o papel das descobertas científicas no episódio do advento da radioatividade. Discussões desse tipo demonstram o quanto é imprescindível uma mudança no Ensino de Química, e como episódios históricos da Química favorecem esse processo de discussão da natureza da ciência, o que também acreditamos poder ser realizado por meio de textos históricos de divulgação científica em Narrativas Históricas.

\section{ASPECTOS METODOLÓGICOS}

As categorias adotadas no estudo referem-se às características enunciativas propostas por Bakhtin (1929/1995)58 que definem os gêneros discursivos, e se materializam no conteúdo temático, composição do enunciado e estilo verbal, não é nosso objetivo definir um novo gênero discursivo aos textos analisados. Como categorias de análise dos enunciados temos a representação feita no Quadro 1.

As categorias qualificam o discurso da divulgação científica dos textos de João Ribeiro, possuindo três aspectos essenciais conforme discutido na seção anterior. Em conjunto com as categorias foi utilizada a análise de conteúdo documental (BARDIN, 2011) ${ }^{59}$ como apoio a análise e interpretação textual.

Quadro 1: Esquema das categorias de análise das características enunciativas adaptadas de Bakhtin (1929/1995).

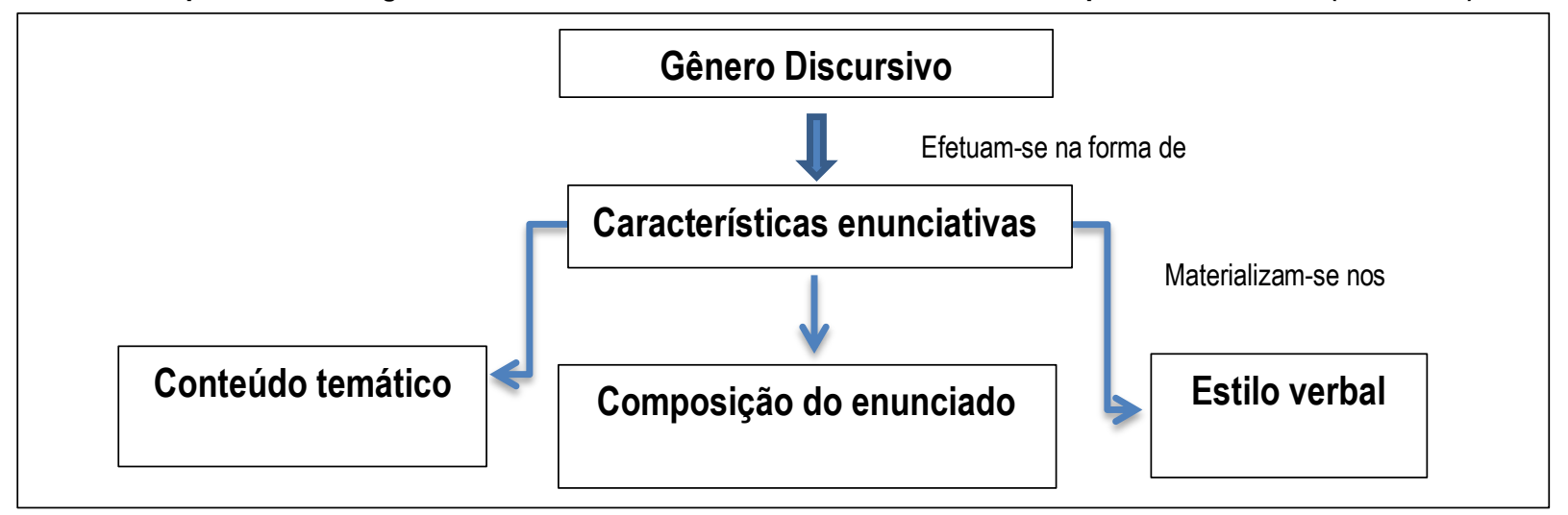

57 Jennyfer Alves Rocha; Adjane da Costa Tourinho e Silva, "Compreensões de alunos de nível médio sobre descoberta: discussões em torno do episódio da descoberta da radioatividade em uma sequência de ensino e aprendizagem" Investigações em Ensino de Ciências 24 (2019): 56-71, https://www.if.ufrgs.br/cref/ojs/index.php/ienci/article/view/1231/pdf (acessado em 02 de dezembro de 2019).

58 Ibid., 5.

59 Laurence Bardin. Análise de conteúdo. (São Paulo: Edições 70, 2011). 
Optou-se neste artigo pela análise de três textos históricos de divulgação científica do autor, intitulados por "Einstein e a Questão do Ensino" (21/03/1922) (T1), "O Mystério da Vida" (02/02/1921) (T2) e "A Nova Theoria dos "Quantuns"' (11/03/1921) (T3), ambos publicados no O Jorna/60. A escolha dos textos ocorreu de forma aleatória de um universo de vinte e dois (22) textos com temáticas diversas, optamos por expressar análises do material de divulgação científica que tratam de conhecimentos relacionados à Química, Física e Ensino.

Analisamos os textos nas categorias enunciativas: conteúdo temático, composição do enunciado e estilo verbal (Quadro 1). Além disso, analisamos a categoria de natureza da ciência (descoberta científica) (LAKATOS, 199961/ KUHN, 199862). A escolha de analisar os textos na categoria de natureza da ciência em relação a descoberta científica se deu por conta do perfil característico dos textos de divulgação científica em torno de novidades científicas.

A discussão dos resultados é apresentada considerando a descrição dos textos inicialmente, em seguida tratamos as categorias assumidas com a inclusão de recortes que dão significado as características enunciativas, seguido ao final de cada categoria por uma contribuição levantada a construção de $\mathrm{NHs}$, por fim discutimos a categoria de aspecto de natureza da ciência.

\section{RESULTADOS E DISCUSSÃO}

Iniciamos esta discussão descrevendo de maneira geral o conteúdo dos textos analisados na ordem descrita na metodologia relacionando com as motivações da divulgação científica do divulgador.

O primeiro texto é intitulado Einstein e a Questão do Ensino (T1). O divulgador coloca em cena, a discussão sobre o ensino na visão do físico Albert Einstein, em especial o ensino da matemática e línguas. Trata-se da descrição de uma entrevista concedida por Einstein em que ele fala de vários assuntos, ao longo do texto a entrevista é descrita nos principais pontos do pensamento de Einstein sobre como o ensino deve ser abordado, principalmente em matemática e línguas. $O$ texto apresenta uma faceta do cientista Albert Einstein que já era discutida nesse período, e que é objeto de estudo de outros autores na atualidade, sua visão sobre a educação é considerada humanista (MEDEIROS; MEDEIROS, 2005)63, nesse período Einstein já usufruía de prestígio internacional na comunidade de físicos e entre o público comum.

\footnotetext{
60 Nota. Jornal fundado em 1919, de circulação no Rio de Janeiro, posteriormente foi comprado por Assis Chateaubriand, passando a fazer parte de seu grupo de comunicação.

61 Ibid., 9.

62 Ibid., 9.

${ }^{63}$ Cleide Farias de Medeiros; Alexandre Medeiros, "Einstein e sua concepção de ensino" Física na Escola 6 (2005): 29-31, http://www.sbfisica.org.br/fne/Vol6/Num2/a10.pdf (acessado em 22 de maio de 2020).
} 
O segundo texto é denominado O Mystério da Vida (T2). João Ribeiro focaliza na divulgação de uma hipótese acerca do surgimento da vida proposta pelo professor estadunidense Troland, da Universidade de Havard. 0 articulista não considera esta uma doutrina muito original, indicando que 0 próprio pesquisador não se propõe a resolver todos os mistérios da vida. Ao ensejar a discussão, é apresentado num enunciado, a grande conclusão de Troland que considera que o mistério único é a "catálise dos químicos". Para o professor Troland, a vida é um fenômeno catalítico. A referência da hipótese divulgada está associada a proposições do próprio químico Wilhelm Ostwald, este, quando se colocou aos estudos da catálise propôs categorias de tipos de catálise, dentre elas estava a catálise enzimática, entendida como um processo catalítico envolvido em reações biológicas (PEREIRA, 2015)64.

Após uma breve explicação da teoria do professor, João Ribeiro retoma a conceituação proposta por Ostwald, reconhecido pelo jornalista como importante químico contemporâneo. No decorrer do texto toda uma explicação é detalhada em volta do que são catalisadores, agentes catalíticos, enzimas, tudo articulado no sentido de expor a hipótese do pesquisador que afirma ser em última análise os fenômenos da vida oriundos de uma ação infinitesimal, influenciados por fenômenos catalíticos, inclusive doenças como provavelmente originadas de processos auto catalíticos. O texto do divulgador num pequeno parágrafo questiona o papel das teorias e como o conhecimento científico é provisório.

O terceiro texto tem por título A Nova Theoria dos "Quantuns" (T3). O texto adentra ao assunto que é a "famosa teoria dos quantuns", marcando uma época na Física Geral, discutindo os meandros das relações entre a teoria de Max Planck e a teoria de Einstein, utilizando um comentário que afirmava ter sido a teoria dos quantuns deixada de lado pela relatividade. Descreve que a teoria dos quantuns destrói um pensamento aristotélico que afirmava dogmaticamente serem todos os movimentos contínuos e ininterruptos. Para ele, desde então, a teoria de Planck resolveu inúmeras indagações que foram adiadas à "quantunidade", trazendo uma nova compreensão aos físicos. O divulgador cita o uso da nova teoria por Einstein em suas pesquisas, e por Niels Bohr em seu modelo atômico.

Ao término do artigo, o divulgador tece comentários sobre a influência das ciências da natureza nas ciências sociais quanto às suas teorias e hipóteses. No comentário do divulgador o século XX aponta para uma nova crença em que os saltos podem acontecer, se referindo ao conceito de salto quântico, 0 que mostra haver uma influência da cultura científica na interpretação de outros aspectos da vida humana, algo comum ao período, apesar de a crença na ciência esta sendo deteriorada pós-primeira guerra mundial, fruto de um processo em curso desde o fim do século XIX.

\footnotetext{
64 Letícia dos Santos Pereira, "Considerações sobre o energeticismo e a catálise na obra de Wilhelm Ostwald" (Dissertação de mestrado, Universidade Federal da Bahia, 2015), 39-66.
} 
Um aspecto a ser considerado Como descreve Feldens, Dias e Santos (2010)65 é que o fato de a energia ter sido quantizada por Planck o resultado não foi entendido totalmente em sua dimensão, obtendo significado apenas quando Albert Einstein explicou o efeito fotoelétrico, Planck também sabia que a hipótese possuía limitações. Quando se analisa o texto de João Ribeiro publicado em 1921 observa-se que esses aspectos iniciais parecem estar resolvidos 21 anos depois da apresentação de Planck (Ano 1900) ter ocorrido, isso explica porque o divulgador faz uma descrição do processo até então, como algo consolidado.

Feita a apresentação dos textos para que possamos ter uma noção do conteúdo do material segue agora a discussão com as categorias elencadas na abordagem metodológica.

\section{Conteúdo Temático}

Esta categoria de análise é marcada pela exposição de uma característica que é manifesta nos textos de divulgação científica analisados, que é a pluralidade de temas trabalhados, em questão tem-se essa mesma característica de produção em textos históricos, esta afirmação é apoiada pela pluralidade temática dos textos escritos pelo divulgador João Ribeiro.

Por conta da pluralidade de temas, os textos analisados envolvem o leitor sem a preocupação imediata de adentrar a notícia principal, procurando contextualizar a origem da escrita do texto (T1), é possível ver isso na descrição da notícia da entrevista feita com o físico Albert Einstein, semelhante a uma resenha do livro que consta a entrevista, o texto não se propõe a ser exaustivo conceitualmente, ficando na divulgação da descrição e da crítica ao ensino das línguas em detrimento da matemática feita por Einstein ao seu entrevistador, ao mesmo tempo há uma crítica ao ensino da matemática pelo viés de que é necessário transformar o ensino desta disciplina, responsabilizando o professor pelo sucesso ou não do estudante, neste sentido observa-se uma marca de didática no conteúdo, como forma de tentar de alcançar o leitor do jornal com a discussão ensejada, conforme vemos no fragmento do texto.

"[...], todavia, tenho dúvidas a este respeito, e não estou convencido de que esses tormentos se depreendem da ausência de talento dos estudantes. Inclino-me muito mais a admittir em taes casos a culpa e responsabilidade dos mestres. Muitos desses professores gastam enorme tempo formulando "questões para descobrir o que 0 alumno não sabe", enquanto que a verdadeira arte de questionar deve ter o proposito de "descobrir o que o alumno sabe ou é capaz de saber" (Fala de Albert Einstein citada no texto)

\footnotetext{
${ }^{65}$ Bruno Feldens.; Penha Maria Cardoso Dias.; Wilma Machado Soares Santos, "E assim se fez o quantum..." Revista Brasileira de Ensino de Física 32 (2010): 2602-1 - 2602-11.
} 
Para entendermos mais esse perfil ribeiriano, e os motivos pelo qual o texto divulga algo com este conteúdo trazemos um caso de demonstração crítica direcionada ao ensino e às práticas educacionais de sua época. Envolvendo-se numa polêmica com o Dr. Rodolfo Von Ihering, do Jornal Estado de São Paulo, a respeito da inclusão das Ciências Naturais no currículo das disciplinas do curso ginasial, João Ribeiro se pôs contra essa inclusão. Colocou-se, nesse caso, do lado das Ciências Humanas, considerando que, para formar humanos naquele nível de instrução, não eram necessárias as Ciências Naturais. Afinal de contas, como ele argumentara, Aristóteles, Eliano e Plínio não seriam chamados de homens cultos só porque não sabiam como funciona a circulação do sangue ou porque ignoravam que a baleia não é um peixe (LEÃO, 1934)66.

Em sua crítica, o divulgador propõe a criação de uma Escola de Vocação para alunos e professores, como as criadas nos Estados Unidos e na Alemanha, pois, em sua concepção todos os seres humanos têm a sua vocação, não há inúteis. Outra particularidade é a de que Ribeiro se apresenta partidário do ensino técnico, criticava o excesso de teorias no ensino, o que importava para ele era 0 contato direto com as coisas. Considerava pedantes os pedagogos, tendo sua preocupação com o ensino, manifestando suas opiniões desde 1890, à época assegurava que enquanto a República67 não cuidasse desse assunto não teria feito nada pelo Brasil, e denunciava casos em que pessoas sem formação adequada ocupavam postos no ensino, uma espécie de Estado de anarquia, dentre outras aberrações $($ LEÃO, 1934)68.

Retomando a discussão apresentamos em oposição à análise do parágrafo anterior fragmentos do texto T2 para justificar ser este, um texto mais conceitual, sem abrir mão de aproximações conceituais:

[...] Há substancias que são poderosos determinantes de acção chimica, simplesmente pela presença, sem affinidades e sem que sejam affectadas pela acção que produzem fora de si mesmas. São esses os agentes catalyticos [...]

[...] Esses agentes no processo vital são conhecidos pelo nome de "enzymos" (fermentos orgânicos). Esses fermentos catalysadores não se modificam, mas emprestam velocidade á machina á maneira do óleo lubrificante. Ahi reside o segredo principal da theoria.

\footnotetext{
66 Múcio Leão, João Ribeiro: estudos críticos. (Rio de Janeiro: Ed. Alba, 1934).

67 Nota. O divulgador se referia a "República do Estados Unidos do Brasil", nome atribuído ao país após a proclamação da república em 1889.

68 Ibid.
} 
No trecho o autor deixa a entender que os catalisadores são agentes que possuem vida própria, trata-se de um tipo de divulgação de uma questão de pesquisa, colocada muito mais como uma hipótese de surgimento da vida, do que a divulgação de resultados sobre o assunto, este é um exemplo do uso da temática associado ao aspecto do estilo verbal, nesse conteúdo há ocorrências de aproximações que vinculam o entendimento do leitor com o conhecimento científico, o que no ensino de ciências pode ser conceituado como uso de analogias e aproximações, que precisam ser levadas em consideração em sua linguagem para evitar a formação de uma concepção equivocada do conteúdo.

O último texto (T3), lida com a propositura teórica do físico Max Planck, localizando a teoria como uma nova visão que se contrapõe a mecânica clássica, são discutidas questões pontuais que a teoria propõe resolução, e que eram consideradas anomalias pela mecânica clássica, mostrando que a teoria veio para ficar e que os físicos da época iriam se deter no seu desenvolvimento.

Desde logo a doutrina de Max Planck foi como uma chave para a solução de numerosos enigmas, cuja decifração parecia adiada. A "quantunidade" da energia verificada nas radiações caloríficas se estendeu experimentalmente a qualquer espécie de radiação, optica electrica, ou outra qualquer. E assim toda a physica teve que reformar as suas hypotheses anteriores.

O apelo nacionalista ensejado por João Ribeiro caracteriza sua divulgação científica como nacionalista aos termos do seu tempo (SANTOS, 1981) ${ }^{69}$ e, ao mesmo tempo, antenada com os centros de produção científica da época. Entende-se que o texto T3 analisado é de vanguarda porque estava antenado ao desenvolvimento da teoria quântica (1900-1922), um período efervescente para a teoria, não só entre os físicos, mas para a sociedade que estava interessada no assunto (CRUZ, 2011)70.

Observa-se uma pluralidade de conteúdos na escrita dos textos, apesar de todos tratarem dos conteúdos a que se propõem, alguns são mais conceituais do que outros, é o caso dos textos T2 e T3, por outro lado, T1 é mais didático considerando o período do texto. Quanto a contribuição para as NHs ressaltamos a possibilidade da pluralidade de conteúdos para a construção desse tipo de material, estando a disposição de pesquisadores e professores com fácil acesso na Hemeroteca Digital da Biblioteca Nacional, o uso desses textos associado a outras obras historiográficas para abordar episódios históricos enriquece mais ainda o trabalho pedagógico do professor na construção e uso de uma NH.

\footnotetext{
69 Vera Lúcia Salles de Oliveira Santos, "João Ribeiro como jornalista científico no Brasil (1895-1934). 1981" (Dissertação de mestrado, Universidade de São Paulo, 1981).

70 Frederico Firmo de Souza Cruz, "Mecânica quântica e a cultura em dois momentos," in Teoria quântica: estudos históricos e implicações culturais, org. Olival Freire Junior, Osvaldo Pessoa Junior \& Joan Lisa Bromberg (Campina Grande: EDUEPB; Livraria da Física, 2011): 301.
} 


\section{Estilo Verbal}

Nos textos históricos de divulgação científica estudados é muito usada a linguagem que procura descrever os acontecimentos e avanços na ciência, se valendo de recursos como exemplificações e pessoalidade na descrição. Além disso, há citação e descrição de conceitos, hipóteses e teorias, sem muito aprofundamento, apenas citações que a nosso ver são exigidas durante a escrita do texto, tanto para conhecimento do leitor, como para conceder autoridade a quem escreve. Em produção de NHs o cuidado no trato com esse aspecto da linguagem deve ser considerado, principalmente com conceitos que sofreram alteração, assim como a abordagem deles deve ser feita avaliando também o tratamento aos conceitos no período histórico.

A análise dos textos proporcionou detectarmos essas características. No texto 1 conceitos como "curriculum" "ensino" "linguagem" estão presentes, no texto 2 há um uso recorrente do conceito de enzimas, bem como da analogia "fermento" para aproximar os conceitos de enzimas ao de catalisadores, outra analogia se dá ao relacionar o conceito do aumento de velocidade com a ação do catalisador, estabelecendo ao argumento a relação do que é biológico e químico com o surgimento da vida, e no texto 3 tem-se conceitos como movimentos contínuo e ininterrupto, teoria das ondulações contínuas, natureza ondulatória da luz, natureza quântica da energia, reflexos dos pressupostos quânticos nos trabalhos de Albert Einstein e Niels Bohr (teoria atômica).

Analisando o estilo verbal é possível estabelecer comparações ou elos na abordagem de como eram os conceitos utilizados na época pelos cientistas, com os utilizados em textos históricos de divulgação científica ${ }^{71}$ escritos em período semelhante, e que serão contados por meio do narrador ${ }^{72}$ em NHs, levando o estudante a se envolver na história contada, sendo possível alcançar a aplicação e discussão de aspectos de natureza da ciência como a observação, inferência e entidades teóricas na ciência e teorias e leis científicas (LEDERMAN et al., 2002) ${ }^{73}$, aproximando-os da realidade da atividade científica.

\section{Composição do Enunciado}

Há presente nos textos do autor uma manifestação contundente da sua individualidade, tanto na escolha dos assuntos divulgados como na construção dos textos. É possível que ele tenha escrito dessa forma por ter sido influenciado pelo Romantismo. O período romântico se caracteriza pela descrição dos

\footnotetext{
${ }^{71}$ Nota. Em Narrativas Históricas em relação ao aspecto literário, um elemento intitulado "eventosmarco", é o responsável no material por estabelecer a sequência de eventos ali tratada, por isso a discussão no parágrafo.

72 Nota. Segundo Norris et al. (2005) o efeito do "narrador" considera um sujeito definido ou indefinido que conta a história ao longo da narrativa.

73 Ibid., 9.
} 
fenômenos em seus detalhes, considerando as ideias como norteadoras da realidade. $O$ apego de João Ribeiro à cultura alemã é forte (alinhado ao romantismo alemão), evidenciando que seus escritos estão permeados pela influência do movimento que, no Brasil, eclode no século XIX. Souza (2010)74 explica que o romantismo alemão foi para mais além do ocorrido em outros países, alcançando inclusive a filosofia, a ciência e a religião (OLIVEIRA, 2017)

Havia no divulgador um apelo nacionalista, no desejo que alimentou de ver o Brasil equiparar-se aos países mais evoluídos no campo da pesquisa científica, como já era a Alemanha. Por isso, muito da sua escrita de textos de divulgação científica era marcada por esse sentimento de divulgar a ciência para informar e formar uma cultura científica no público leitor dos jornais. A expectativa por um país melhor, bem desenvolvido, nacionalista e com características da cultura germânica aplicadas ao Brasil é a intenção que move João Ribeiro a procurar atualizar a população brasileira letrada.

Sustentamos a ideia que promover uma cultura científica na nação brasileira era de seu interesse, assim como ocorrera na Alemanha. Argumentamos desta maneira, considerando que suas primeiras produções de divulgação científica foram a partir de 1895, ano em que Ribeiro fazia sua primeira viagem pela Europa, na condição de emissário do governo brasileiro, para realizar um estudo sobre educação, em particular sobre como ocorria o ensino de História em países europeus. Visitou a Itália, Inglaterra, França e Alemanha, permanecendo um ano na Alemanha, onde escrevia artigos e os enviava a jornais brasileiros como o "Jornal do Commércio", "Commércio de São Paulo" e "O Dia" (OLIVEIRA, 2017, p. 54$)^{76}$.

Assim, os textos T1 e T3 são configurados dessa maneira, em geral há uma introdução contextualizando algum aspecto sociocultural, seguido do desenvolvimento da ideia, descrição da teoria ou conhecimento divulgado, finalizando com uma retomada sociocultural. Tomamos como exemplo trechos do texto T3.

Não é só assombroso o movimento scientifico e philosofico da Allemanha nestes últimos annos. [...] A literatura de ficção allemã também é para nós uma terra incógnita e indesejável [...]. [...] Está nesse número a famosa theoria dos "quantuns" que marca epoca na sciencia da physica geral [...]. É a - "Quantentheorie" - de Max Planck. [...] Todos os movimentos eram considerados, dogmaticamente, contínuos e ininterruptos

\footnotetext{
74 Maria Cristina dos Santos de Souza, "A Nathurphilosophie como concepção de mundo do romantismo alemão" AISTHE Revista de Estética 4 (2010): 31- 47

https://revistas.ufrj.br/index.php/Aisthe/article/view/11888/8601 (acessado em 03 de março de 2016)

75 Filipe Silva de Oliveira, "A ciência do século XIX na visão do jornalista João Ribeiro em artigos de divulgação científica (1895-1934)" (Dissertação de mestrado, Universidade Federal de Sergipe, 2017), 144.

76 Ibid., 17.
} 
[...]. Todo o século XIX, elle mesmo o relembra, viveu impregnado de evolucionismo. $A$ evolução continua foi a theoria tanto da natureza como da história [...].

Por ser eclético na escrita, os textos podem ser considerados transversalistas, em se tratando de abordar aspectos socioculturais do seu tempo com os conhecimentos científicos divulgados, uma característica relevante na elaboração de $\mathrm{NHs}$, visto que os aspectos histórico (considerar o uso de viés historiográfico) e literário são estruturantes a esse tipo de material (KLASSEN, 200977; NORRIS et al., 200578; KUBLI, 200179).

\section{Natureza da Ciência (Descoberta científica)}

Nos textos analisados observa-se a divulgação de hipóteses científicas, descrições de avanços na ciência como o caso da mecânica quântica, fazendo contraponto com a mecânica clássica, e no ensino da matemática, como é o caso do texto que divulga a entrevista de Einstein, este, traz uma inquietação provocada nesta entrevista acerca da necessidade do professor não somente saber o que vai ensinar, mas saber ensinar, neste sentido algo instigante à época, não sendo, porém, profundo nesta reflexão. Trazemos abaixo fragmentos do texto T3 para apresentar como a descoberta científica era discutida ao público leigo.

"A "theoria dos quantuns" destroe um antigo preconceito que dominava toda a physica, o dogma artistotelico que sempre enunciou em latim: "Natura non facit saltus". Todos os movimentos eram considerados, dogmaticamente, contínuos e ininterruptos. Essa idéa geral que dominou toda a sciencia parece agora absolutamente insustentável. A natureza, realmente dá saltos e saltos de qualidade singular."

"Alguns physicos que estavam diente d'essas difficuldades, recorriam a gratuitas correções; Max Planck resolveu atacar a theoria no seu reducto e conseguiu demonstrar que o espantalho não valia coisa alguma. Com experiências sucessivas chegou a verificar que a radiação do calor não é continua, mas vae por pequenos saltos numerosos e como poude medir esses saltos em "quantuns" elementares, formulou a sua famosa theoria dos "quantuns."

\footnotetext{
77 Ibid., 6.

78 Ibid., 6.

79 Ibid., 6.
} 
Na literatura há críticas (KUHN, 1998) ${ }^{80}$ a atribuição da descoberta científica de algo a um

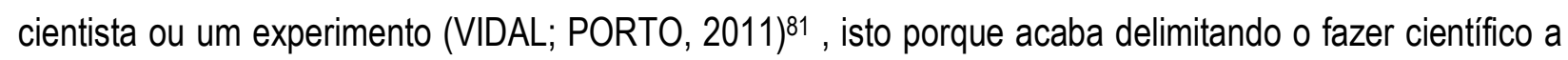
espaço e tempo, personificando em indivíduos os avanços científicos, e criando uma visão estereotipada do fazer científico, sendo possível inclusive cometer injustiças, ou até erros históricos e conceituais. 0 papel do professor das ciências da natureza é questionar esses dogmas que em geral são falsos, resultado de uma construção da história da ciência de concepção positivista, isto acaba por interferir na compreensão de estudantes e professores sobre a natureza da ciência. No ensino de química este tipo de abordagem tem sido criticada, e propostas de reconstrução histórica ou revisitação a episódios históricos estão auxiliando a clarear estas questões (VIDAL; PORTO, 2011) 82.

O material analisado é útil na promoção destas discussões em sala de aula na medida em que professores ao introduzirem NHs construídas sob esses textos em seu planejamento de ensino e em sequências didáticas proporcionarão a estudantes compreenderem que as descobertas científicas não acontecem do acaso, e que existe um desenvolvimento no processo de uma nova descoberta que pode levar anos, incluindo experimentos e hipóteses bem sucedidos ou não, além de uma aceitação por pelo menos uma parte dos pesquisadores da área, sendo essas e outras práticas científicas introduzidas ao processo de ensino pelas NHs (SCHIFFER; GUERRA, 2019) 83.

\section{CONSIDERAÇÕES FINAIS}

Textos históricos de divulgação científica são um excelente material de pesquisa, visto que foram escritos em períodos históricos que geralmente se entrelaçam ao desenvolvimento das ciências, podem ser úteis a discussão de questões conceituais, de aplicação, e contexto desses às pesquisas como fontes primárias ou secundárias. Estes materiais quando tratados de maneira conjunta com a abordagem internalista e externalista da história da ciência podem favorecer a compreensão da natureza da ciência e seu desenvolvimento, bem como possibilitar a construção de materiais didáticos ainda tão escassos para esta abordagem de ensino.

Pode-se concluir também com base na análise das características enunciativas discutidas, que textos de divulgação científica escritos pelo divulgador João Ribeiro são marcadamente identificados pela apresentação de conteúdos próprios pelo viés do autor, com uma variabilidade temática considerável, não somente na apresentação do conteúdo científico, assim como no estilo composicional do texto. No caso apresentado, observa-se que o divulgador é bem eclético na sua escrita, há textos bem didáticos, e textos com características mais científicas. Uma característica pontual referente ao material analisado e que

\footnotetext{
80 Ibid., 9.

81 Ibid., 10.

82 Ibid, 10.

${ }^{83}$ Ibid, .6.
} 
consideramos ser próprias do autor é a transversalidade de características socioeconômicas com a ciência e a cultura, aspectos relevantes para apropriação na abordagem histórico-filosófica na elaboração de material didático como estudos de caso e narrativas históricas.

Apresentamos as Narrativas Históricas como propícias à recepção de textos dessa natureza para uso na elaboração em conjunto com outros documentos. As características enunciativas discutidas pela teoria bakhtiniana para os textos históricos analisados neste artigo auxiliam no fornecimento de mais compreensões, pois as categorias se alinham ao entendimento discursivo contextual dos textos que podem ser úteis ao processo de construção de uma $\mathrm{NH}$.

Com este artigo, acreditamos fornecer a comunidade de pesquisa que tece relações entre ensino de ciências e história da ciência, uma discussão acerca de como estes e outros materiais podem ser utilizados em diversos campos da pesquisa como a investigação em torno da divulgação científica e a elaboração de materiais didáticos pela abordagem histórico-filosófica.

\section{SOBRE OS AUTORES:}

Filipe Silva de Oliveira Universidade Federal de Sergipe, Campus São Cristóvão, Brasil oliveiradefs@gmail.com

Edson José Wartha Universidade Federal de Sergipe, Campus São Cristóvão, Brasil ejwartha@gmail.com

Artigo recebido em 19 de março de 2020 Aceito para publicação em 09 de junho de 2020 